Deetjen, P. \& Kramer, K. (1961) Die Abhängigkeit des $\mathrm{O}_{2}$-Verbrauchs der Niere von der Na-Rückresorption. Pflügers Arch. Physiol. 273, 636.

DunN, J.S., Gillespie, M. \& Niven, J.S.F. (1941) Renal lesions in two cases of crush syndrome. Lancet, ii, 549.

Hamburger, J. \& Mathé, G. (1952) Métabolisme de l'Eau. Flammarion, Paris.

Joekes, A.M., Mowbray, J.F. \& Dormandy, K. (1957) Oliguria with urine of 'fixed' specific gravity. Lancet, ii, 864.

KolfF, W.J., Berk, H.Th.J., ter Welle, Zr M., VAN Der LEY, VAN DIJK, E.C. \& VAN NoORDWIJK, J. (1944) The artificial kidney: a dialyser with a great area. Acta med. scand. 117, 121.

KRAMER, F. (1967) Renal circulation and urinary secretion. 32nd Belgian Congress of Urology, 1967.

LATTIMER, J.K. (1945) A plan for the management of anuria. J. Urol. 54, 312.
Munck, O. (1958) Renal Circulation in Acute Renal Failure. Blackwell Scientific Publications, Oxford.

Oliver, J., MacDowell, M. \& Tracy, A. (1951) The pathogenesis of acute renal failure associated with traumatic and toxic injury. Renal ischemia, nephrotoxic damage and the ischemuric episode. J. clin. Invest. 30, 1305.

Shaldon, S., Walker, J.G., Lawson, J.R., Ryder, J. \& Sylvan, H. (1963) The renal blood in acute renal failure measured by renal arterial infusion of indocyanin green. Proc. Soc. exp. Biol. (N.Y.), 112, 932.

SiRota, J.H. (1949) Carbontetrachloride poisoning in man. I. The mechanisms of renal failure and recovery. J. clin. Invest. 28, 1412.

Wickham, J.E.A. \& Sharma, G.P. (1965) Endogenous ammonia formation in experimental renal ischaemia. Lancet, i, 195.

\title{
The Epping Jaundice after two years
}

\author{
HARRY KOPELMAN
}

St Margaret's Hospital, Epping, Essex

THE outbreak of liver disease which occurred in Epping and the surrounding district in 1965 has been fully described by Kopelman et al. (1966a) and Kopelman, Scheuer \& Williams (1966b) and summarized in a J.A.M.A. Editorial of the same year (Anon., 1966). Briefly, eighty-four persons were known to have been affected after eating bread made from flour contaminated by a chemical hardener $4 \cdot 4^{\prime}$-diaminodiphenyl methane, spilled from its container while both were in transit. The hepatic lesion so produced was shown by needle liver biopsy to be unique and showed changes in the portal zones of cholangitis early in the disease, but later showed intense centrilobular cholestasis and hepaticcellular necrosis (Kopelman et al., 1966b). All patients made a good clinical recovery and in one case a liver biopsy taken some 4 months after the onset showed only minor changes from normal.

Subsequent examination of some claimants for compensation revealed a large variety of symptoms ascribed to, or said to have followed, the jaundice. These symptoms included great intolerance to fats, excessive flatulence, constipation, depression and lack of concentration, irritability, general fatigue, intellectual deterioration and, in two cases, visual disturbance. Of fourteen cases examined, ten had symptoms of some severity when seen 7-23 months after the onset of the disease. It was therefore considered that some help in assessing the cause of these symptoms might be obtained by reviewing as many cases as possible after an interval of 2 years from the onset of the disease.

\section{The investigation}

Patients known to have had the disease were asked to answer a simple questionnaire by their general practitioner and it was arranged for them to have blood taken for liver function tests. The questionnaire enquired into their general wellbeing, weight, appetite, food which upset them, bowel function and motions, symptoms of pain, itching, nervous trouble, eye or ear trouble and any other symptom they might have. Liver function tests consisted of estimating plasma proteins, serum bilirubin, the alkaline phosphatase, turbidity tests and serum aspartate transaminase. In addition most patients had a blood count taken. Forty-three patients had their questionnaires completed and returned and liver function tests were done in all but two cases. The fortythree patients included eleven who had previously been examined for insurance purposes.

\section{The results \\ General fitness}

Patients were asked whether they were very well, not quite $100 \%$, or had troublesome symptoms. Of the forty-three replies twenty-eight $(63 \%)$ said they were very fit, eleven $(23 \%)$ that they were not quite $100 \%$ and only four had troublesome symptoms. One of these four, whose 
case was fully investigated and is described later, is now very fit and well. The other three cases were ones previously examined with regard to compensation claims.

\section{Weight}

Twenty-one patients were back to their normal weights, ten had gained weight (the maximum being $21 \mathrm{lb}$ ) and twelve had lost weight (the maximum being $28 \mathrm{lb}$ ). Some of those with weight loss admitted to dieting to maintain this loss.

\section{Food-intolerance}

Thirty-two patients would not admit to any food intolerance although eight $(18 \%)$ did complain that fats upset them and they avoided these. Four found their alcohol tolerance reduced and one patient was intolerant to fruit.

\section{Increased tiredness}

This was complained of by twelve (28\%) patients, often accompanied by a loss of zest. Apart from two cases, again seen previously for compensation claims, this did not give rise to any impairment of work or activity.

\section{Other symptoms}

There was no significant change in bowel habit or in the nature of the motions, although a few did comment that their constipation was worse. In four cases itching, all of a mild degree, had persisted, but in one itching had occurred before the disease. In only one of these cases the aspartate transaminase was raised to 54 Karmen units, the other tests being normal. Four patients, two of whom were medical practitioners, thought that their hair had become grey more rapidly following the onset of the jaundice. One patient gave a history of intermittent blurring of vision in one eye which had persisted; this was one of the two cases with eye symptoms previously mentioned.

Two patients had successfully given birth to healthy infants without trouble or complications.

\section{Biochemical findings}

Six persons were found to have slightly raised values of aspartate transaminase. In five cases these ranged from 32 to 54 Karment units, but were not accompanied by other abnormalities. except one patient who had a serum bilirubin of $1.2 \mathrm{mg} / 100 \mathrm{ml}$. The sixth case, in addition to an aspartate transaminase of 76 Karmen units, had an alkaline phosphatase of 22 K.A. units, the bilirubin being $0.6 \mathrm{mg}$. This patient's case is described in detail later. Of these patients one complained of some itching, three tired more easily than before and two had difficulty with fat or rich food.

One other patient had a raised serum bilirubin of $1.8 \mathrm{mg} / 100 \mathrm{ml}$. In this case all other function tests were normal and she was well, although now aged 86 years.

The alkaline phosphatase was raised in two persons. the one described above, with 22 units, and one other case with 14.8 units, but with other tests normal. This latter patient had numerous symptoms of some severity.

Bromsulphthalein retention tests were done on fifteen patients, all of whom showed normal values at $30 \mathrm{~min}$. In one patient (Case 7, Kopelman et al., 1966b) with prolonged jaundice over some months, a $51 \%$ retention at 5 months from the onset did not return to normal values for nearly a year.

One patient who went to New Zealand soon after recovery from an acute attack, had a BSP retention of $12 \%$ at $45 \mathrm{~min}$ some 18 months after the onset, although all her other tests were normal. She complained of tiredness, but also has ischaemic heart disease.

Only one person had symptoms directly referable to the liver and more than one abnormal test of significance. This case has been fully described previously by Kopelman et al. (1966b) as Case No. 3 and was one of those who had a liver biopsy in the acute phase. His further progress will be described in more detail.

Case 3. This patient was a 70-year-old man with an acute onset of symptoms, a raised bilirubin reaching a maximum of $9.9 \mathrm{mg} / 100 \mathrm{ml}$. an alkaline phosphatase of $77.2 \mathrm{~K}$.A. units and an aspartate transaminase of $44 \mathrm{Karmen}$ units. Liver biopsy showed typically early changes of the Epping Jaundice. He made a slow but uninterrupted recovery and by 3 months from onset his tests had returned to normal values.

He did not feel completely well and in the following year was seen by a surgical colleague for symptoms resembling biliary colic. Cholecystography showed a faintly opacified gall bladder without evidence of stones. His condition improved but he did not fully recover and lost 2 stone in weight. This year, some 2 years after the onset, he developed attacks of lower abdominal colic, accompanied by rigors and an urticarial rash. Double-dose cholecystography showed a normal functioning gall bladder without stones being seen. Barium studies also showed no abnormalities. Liver function tests, however, showed an alkaline phosphatase of 22 K.A. units and an aspartate transaminase of 76 Karmen units, plasma protein, flocculation tests and serum bilirubin being normal. Tests for carcinoid and other causes of raised alkaline phosphatase were negative. In view of his symptoms, results and past history, a needle biopsy 
was performed. The comment by Dr Peter Scheuer on the section was as follows:

'There is a superficial resemblance to the previous biopsy (1965). However, this does not prove a toxic cause for the present changes. Cholestasis is now absent and eosinophils are less. This may well be large duct biliary disease with cholangitis. There is no indication of chronic progressive liver disease'.

Subsequently the patient has had no further symptoms, his appetite has returned and he has put on weight. He relates his improvement to a severe attack of abdominal pain following the barium meal earlier in the year. It seems probable that he passed a single large biliary stone. His recent tests showed a bilirubin of $0.3 \mathrm{mg}$ alkaline phosphatase of 14.7 K.A. units and an aspartate transaminase of 22 .

\section{Discussion}

Sherlock \& Walshe (1946) studied twenty soldiers following an attack of hepatitis. Eighteen complained of fatigue, six of fat intolerance, and other symptoms such as weight loss (eleven), abdominal discomfort (ten) and anorexia (twelve). In these cases of the so-called posthepatitis syndrome no causal relationship was found between the slight biochemical and hepatic histological changes and the symptoms. Similar biochemical and histological changes were found in sympton-free patients within 6 months of an acute hepatitis. Many of these soldiers were awaiting repatriation and the possible psychogenic basis for the symptoms was discussed. Chuttari et al. (1966) did a clinical assessment 5 years after an outbreak of infectious hepatitis in Delhi (1955-56) involving some 29,300 patients. Three hundred and four cases were interviewed, of which 114 were investigated by biochemical tests and seventy had liver biopsies. Digestive symptoms were present in $18.4 \%$ compared to $10 \%$ of patients' family members without history of the disease and a higher proportion had palpable livers.

In the present series thirty-two out of fortythree had no digestive troubles, but eight $(18.5 \%)$ had some fat or rich-food intolerance, though on the whole of no great severity. Four had a reduction in alcohol tolerance which might be related more to the abstention recommended for some months in all affected cases. There was also an increase in general tiredness and loss of zest in twelve cases (28\%), but, except for two, this did not interfere with or impair their work or other activity. Most of those affected had become reasonably or very fit over the years, but four still did complain of troublesome symptoms. One of these has since regained his full health.

With the one exception, the slight abnormalities in the biochemical tests were in single tests only and it is difficult to assess the slight rise in aspartate transaminase seen in five cases and which were not accompanied by any other biochemical abnormality. Only one of these patients had symptoms of any definite significance. Both the patients with raised alkaline phosphatase levels had symptoms of some severity, but the one investigated and described has shown a marked improvement in his symptoms and in biochemical tests. It is of great interest that the liver biopsy taken some 2 years after the original biopsy showed no evidence of progressive liver disease and that parenchymal changes were slight and cholestasis virtually absent.

The symptoms of the post-hepatitic syndrome bear little relationship to abnormal biochemical tests of liver function or to the later development of post-hepatitic cirrhosis (Sherlock \& Walshe, 1946). In the present series the symptoms which have persisted do not seem, in most cases, related to abnormal tests of liver function. Since these symptoms are mainly subjective it seems likely that vague feelings, such as tiredness, can be attributed more to the severity of the illness than to any specific organ pathology. Some of these patients had been quite ill for a long period in the acute phase of the disease. It is also difficult, as Sherlock \& Walshe found, entirely to dissociate psychological factors in the persistence of symptoms. However, it is of interest that $18 \%$ of patients complained of food intolerance, which is the same proportion as in the Indian Series of Chuttari et al.

There is, to date, no definite evidence of progressive hepatic disease following the initial hepatic lesion of the Epping Jaundice.

\section{Postscript}

One of the patients affected by the Epping Jaundice, a medical practitioner, remembered that he had fed his dog with some crusts from the affected bread and noted that the dog subsequently developed jaundice. An attempt was made to obtain blood from the dog during this period but this unfortunately resulted in the pathologist attempting venesection getting bitten, but no blood was obtained from the dog. Subsequently, a few months ago the dog developed severe diabetes which did not respond to treatment, so that finally the dog had to be destroyed. The diabetes was due to chronic pancreatitis but the liver was found to show only fatty changes compatible with diabetes and no evidence of any chronic liver damage.

\section{Acknowledgments}

I should like to thank the Epping and Ongar general practitioners for their co-operation and help in this follow-up and also express my appreciation of the help of Dr Peter Scheuer, Dr Roger Williams and Mr Peter Sanders. 


\section{References}

Anon. (1966) Editorial: Toxic bread. J. Amer. med. Ass. 196, 1150.

Chuttari, H.K., Sidhu, Wig, K.L., Gupta, D.N., RamaLINGASWAMI, V. (1966) Follow-up study of cases from the Delhi epidemic of infectious hepatitis, 1955-56. Brit. med. J. ii, 676.
Kopelman, H., Robertson, M.H., Sanders, P.G. \& Ash, I. (1966a) The Epping Jaundice. Brit. med. J. i, 514.

Kopelman, H., Scheuer, P.J. \& Williams, R. (1966b) The liver lesion of the Epping Jaundice. Quart.J. Med. 25, 553.

Sherlock, S. \& Walshe, V.M. (1946) The post-hepatitis syndrome. Lancet, ii, 482.

\title{
The value of praecordial pulsations in the diagnosis of heart disease
}

\author{
PATRICK MOUNSEY \\ Royal Postgraduate Medical School, London
}

Palpation of the praecordium is as indispensable as auscultation of the heart in clinical examination of the cardiac patient. Indeed, the two should be practised simultaneously, checking the timing of heart sounds and praecordial movements in relation to one another. To some extent the introduction of the modern binaural stethoscope with its flexible rubber tubes has been a retrograde step, since this instrument is less suited to simultaneous analysis of praecordial pulsations and heart sounds than was the original solid tubular stethoscope invented by Laennec. In the Traité de l'Auscultation Mediate, Laennec (1819) emphasized that his instrument could be used not only to auscultate the heart but also to appreciate accurately the cardiac impulse. $\mathrm{He}$ includes in his book a chapter on the cardiac impulse and states that a forcible impulse should be regarded as the principle sign of cardiac hypertrophy.

Improved methods of recording the cardiac impulse have been slower to develop than has phonocardiography, although apex cardiography was one of the earliest methods introduced for recording the heart beat (Marey, 1878). Apex cardiography suffers from the disadvantage that it is only a record of the relative displacement of a point in an intercostal space in relation to the immediately surrounding area of chest wall. In cardiac diagnosis it is often the displacement of a large area of the thoracic cage by the movements of the underlying heart that is important diagnostically, (as in the left parasternal lift of right ventricular hypertrophy), and not the relative movement of a small area in an intercostal space. To record this, an instrument is required that measures absolute displacement, that is the total movement of the chest wall in relation to a fixed point in space. Various methods have been used for making this measurement, by Dressler in 1937, Eddleman et al. in 1953 and by Beilin \& Mounsey in 1962. We have called our instrument the impulse cardiogram and it aims at being a graphic record of what the physician's hand and fingers feel.

\section{The technique of palpating the praecordium}

It is often a good practice when examining the praecordium to place the whole palm of the hand over the area of the chest that underlies the heart. In this way, one can imagine that one is holding the anterior surface of the heart in the cup of one's hand, thus appreciating both right and left heart events simultaneously. Care should be taken, however, not to assume that pulsations at the apex are always due to the left ventricle, while those in the left parasternal area are due to the right. Although this statement is true probably in about $90 \%$ of patients, in the other $10 \%$ it is misleading. With great enlargement of either left or right ventricle the relationship of underlying chambers of the heart to the praecordium are altered (Fig. 1). Thus, with marked left ventricular hypertrophy this chamber may underlie the whole area of praecordium from the apex beat to the left sternal edge, the right ventricle being pushed over to the right. Similarly, with great right ventricular enlargement this chamber forms the apex of the heart, the left ventricle being rotated posteriorly (Deliyannis et al., 1964). It is more accurate, therefore, when describing praecordial pulsations to relate these to the areas on the chest wall where they are felt, rather than to term them 'right or left ventricular types' of impulse. 